Malte E. Wigand, M.D., Toni Haid, M.D., Michael Berg, M.D., Bernd Schuster, M.D., and Winfried Goertzen, M.D.

\title{
Extended Middle Cranial \\ Fossa Approach for Acoustic \\ Neuroma Surgery
}

\begin{abstract}
The enlarged middle cranial fossa approach was used for removal of acoustic neuromas in 209 cases. Complete tumor removal was accomplished in $96 \%$ of cases. Hearing was preserved in $51 \%$ of cases, with better results in smaller tumors. Our experience with the enlarged middle fossa approach has led us to discard the translabyrinthine approach for removal of acoustic neuromas.
\end{abstract}

Recently, the usefulness of preservation of hearing in acoustic neurinoma surgery has been a controversial subject. The value of preserving severely impaired function must be balanced between the surgical priorities of complete tumor removal and preservation of good facial nerve function.

In an attempt to combine the goals of complete tumor ablation and controlled facial nerve dissection with predictable preservation of hearing, a new technique ${ }^{1-3}$ has been developed for the exposure of the cerebellopontine angle (CPA). Our search for better methods was stimulated by our observation of a remarkable rate of hearing preservation in our material. One has to take into account that not only "serviceable hearing" of the affected ear (as defined by $60 \mathrm{~dB}$ HL in the averaged pure-tone audiogram) is worth preserving but that still worse hearing ability may contribute to the capability of sound localization. From this observation, 4 it can be inferred that also for the discrimination of speech in a free sound field, hearing losses of more than $60 \mathrm{~dB}$ in the operated ear may sometimes be valuable for the unaffected contralateral ear just by contribution to directional hearing. Patients with nonuseful hearing function of their operated ear have also emphasized a better acoustic orientation than when it is occluded by ear plugs.

With regard to these experiences and in order to retain options for future application of hearing aids or implants, the translabyrinthine removal of acoustic neuri- nomas was canceled in our department since 1983 in favor of the enlarged middle fossa approach (EMFA).

\section{TECHNIQUE}

After the formation of a caudally pedicled skin flap over the sleeve with the root of the zygomatic arch in its center and after a Y-shaped transection of the temporalis muscle, a bone flap of 4 by $5 \mathrm{~cm}$ is excised from the temporal squama. The floor of the middle cranial fossa is exposed to the middle meningeal artery (anteriorly), the sigmoid sinus (posteriorly), and the superior petrosal crest (medially). Cautery and transection of the meningeal artery with packing of the foramen spinosum by Oxycel and sharp dissection of the petrosal nerves from the dura helps to mobilize the dura from the bone. Further space for a broad exposure of the CPA can be gained by the resection of the superior petrosal sinus. This maneuver comprises an anterior and a posterior closure by packing the incised sinus with Surgicel (Tabotamp), and the subsequent highfrequency cautery of the isolated segment of the sinus. The direction of the internal auditory canal (IAC) is easily found by bisectioning the angle that is formed by the greater petrosal nerve and by the "gray line" of the superior semicircular canal. The most important step of the procedure consists of an ample bone resection in front of and behind the IAC (hatched area in the sketch of Figure 1)

Skull Base Surgery, Volume 1, Number 3, July 1991 Department of Otorhinolaryngology, University of Erlangen-Nuremberg, Erlangen, Germany Reprint requests: Professor Dr. Wigand, Department of Otorhinolaryngology, University of Erlangen-Nuremberg, Waldstraße 1, D-W-8520 Erlangen, Germany Supported by the F. and T. Marohn Foundation, Erlangen, Germany Copyright (C) 1991 by Thieme Medical Publishers, Inc., 381 Park Avenue South, New York, NY 10016. All rights reserved. 


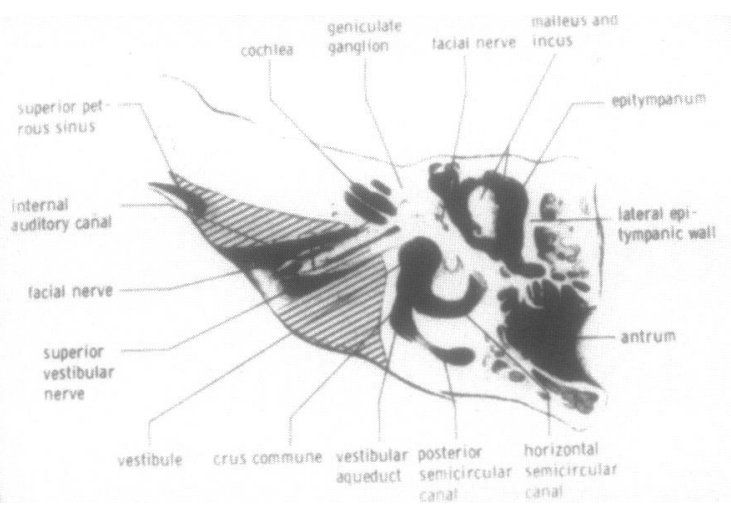

Figure 1. Schematic drawing of a horizontal plane through the temporal bone. By removal of bone material in the hatched area, the cerebellopontine angle is broadly exposed. (Modified after Valvassori)

according to landmarks. ${ }^{5}$ By this bone excision, a broad access to the CPA is achieved, measuring 2.5 to $3.0 \mathrm{~cm}$ in diameter. Deflection of dural flaps of adequate size will open a window for the removal of tumors of sizes up to 3.5 $\mathrm{cm}$.

Immediately after the exposure of the superior surface of the lesion, the facial and superior vestibular nerves can be identified and mobilized from the arachnoid cover of the tumor (Fig. 2). The microscopic control of the meatal fundus and the easy identification of cochlea and labyrinth are the other definite advantages of this procedure. The stepwise intracapsular debulking of the tumor from above allows the dissection of the outer surfaces of the lesion under optical control, and even to pull its primarily hidden posteroinferior compartments into the visual field for the blunt dissection of both arachnoidal adhesions and adherent vessels or nerves. The mobilization of the proximal stump of the tumor from the brainstem or from the cerebellum can be achieved without pressure on these structures. This and the comparatively short

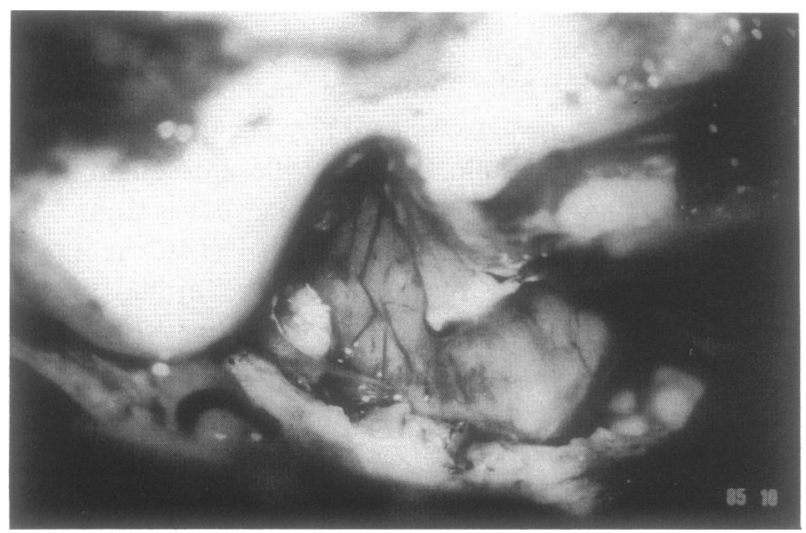

Figure 2. Exposure of an acoustic neuroma by the extended middle cranial fossa approach (left side). The facial nerve is demonstrated on a hook. working distance and direct exposure are other advantages of this technique.

Since, under these observational conditions, it is more relevant for the surgeon rather than the actual size in centimeters, whether the lesion is limited to the IAC, extends into the CPA, or is adherent to the brainstem. We have subdivided our cases into three categories: A, strictly intrameatal; B, extending into the CPA but not adherent to the brainstem, what corresponds to a size of 0.3 to $1.5 \mathrm{~cm}$; and $\mathrm{C}$, broad contact with the brainstem, corresponding to sizes of 3.0 to $4.0 \mathrm{~cm}$ in our material.

Table 1 explains our definition of tumor sizes with regard to the EMFA.

After the complete removal of the tumor, the CPA was explored for meticulous hemostasis utilizing bipolar cautery and eventual compression with Gelfoam and tissue adhesive (Tissucol). The dural and bone defects were then filled by a double layer of periosteum and fascia, also fixed by fibrin glue. The free bone flap was reintegrated by four Vicryl sutures and bone pâté with fibrin adhesive. The reconstruction of the temporalis muscle was followed by the insertion of a Redon drain and a double layer skin suture.

\section{RESULTS}

The following results were based on a retrospective study of the available data retrieved by looking through the hospital charts and by collecting reliable information from the referring ear, nose and throat specialists.

Complete tumor removal was possible in $96 \%$ of 209 documented cases (Table 2). Incomplete ablation was deliberate, in a small series of planned two-stage operations of large tumors with excellent preoperative hearing, or involuntary, due to a subtotal removal because of tight adhesions to large vulnerable vessels at the brainstem in

Table 1. Definition of Tumor Sizes According to Surgical Consequences of the Enlarged Middle Fossa Approach

\begin{tabular}{ll}
\hline $\begin{array}{l}\text { Only intrameatal } \\
\text { Extension into the }\end{array}$ & A: $<11 \mathrm{~mm}$ intrameatal \\
cerebellopontine angle & B: 0.3 to $1.5 \mathrm{~cm}$ in the CPA \\
$\begin{array}{l}\text { Broad contact to } \\
\text { brainstem }\end{array}$ & C: 1.6 to $3.0 \mathrm{~cm}$ in the CPA \\
$\begin{array}{l}\text { Invasion of labyrinth or } \\
\text { middle ear }\end{array}$ & D: all sizes
\end{tabular}

*Tumors of more than $3 \mathrm{~cm}$ in diameter (giant tumors) or penetrating into the middle ear or labyrinth (D) were usually not operated on by the enlarged middlefossa approach.

+ CPA: cerebellopontine angle. 
Table 2. Enlarged Middle Fossa Approach for Acoustic Neurinomas, Complete/Incomplete Tumor Removal

\begin{tabular}{|c|c|c|c|c|}
\hline & \multicolumn{3}{|c|}{ Size } & \multirow[b]{2}{*}{ Total } \\
\hline & $A$ & $B$ & C & \\
\hline Operations (no.) & 25 & 102 & 82 & 209 \\
\hline Complete removal (\%) & 100 & 100 & 90 & 96 \\
\hline $\begin{array}{l}\text { Planned subtotal removal (last } \\
\text { hearing ear, two-stage } \\
\text { otoneurosurgery) (\%) }\end{array}$ & 0 & 0 & 5 & 2 \\
\hline $\begin{array}{l}\text { Incomplete removal (due to } \\
\text { adherence to brainstem) (\%) }\end{array}$ & 0 & 0 & 5 & 2 \\
\hline
\end{tabular}

4\%. Planned incomplete tumor resection was also carried out in cases of bilateral neurinomas, but these data were published separately 6 and not included in Table 2.

Facial nerve function was severely disturbed during the first postoperative year in $13 \%$, but late poor results of facial nerve function (grades 2 to 4 according to the House scale) come to only $6 \%$. Severe neurologic complications have been exceptional (see Table 3).

Besides transitory meningism or meningitis, temporary disorientation or difficulty in speaking over a period of a few days to 2 weeks, there were two patients who had a single epileptic seizure each during the first postoperative month without any recurrence. One fatality occurred among the last 50 cases: A patient died from untreatable brainstem edema, which developed progressively over 3 days after a revision operation 16 hours after the first operation. The patient had shown an excellent postoperative performance but suddenly complained of severe headache, became unconscious, and a revision operation was performed within 40 minutes after the first alarm for a moderate bleeding from both the superior petrosal sinus and a small cerebellar vessel.

The rate of preservation of hearing was slightly improved during the last 2 years. Although the overall percentage for all tumor sizes has been 55\% in the last 100 consecutive cases, it was only $51 \%$ in the complete series

Table 3. Complications of Surgery for Acoustic Neurinoma Via the Enlarged Middle Fossa Approach

\begin{tabular}{lrrrr}
\hline & \multicolumn{3}{c}{ Size } & \\
\cline { 2 - 4 } & \multicolumn{1}{c}{$\boldsymbol{A}$} & $\boldsymbol{B}$ & $\boldsymbol{C}$ & Total \\
\hline Operations (no.) & 25 & 102 & 82 & 209 \\
Postoperative hemorrhage (\%) & 0 & 2 & 2 & 2 \\
$\begin{array}{l}\text { Secondary wound healing (\%) } \\
\text { Delayed cerebrospinal fistula }\end{array}$ & 0 & 1 & 3 & 2 \\
$\quad$ healing (\%) & 8 & 9 & 7 & 9 \\
$\begin{array}{l}\text { Cerebrospinal fluid requiring } \\
\quad \text { 2nd operation (\%) }\end{array}$ & 0 & 3 & 1 & 2 \\
$\begin{array}{l}\text { High-grade permanent facial } \\
\quad \text { paresis (\%) }\end{array}$ & 0 & 4 & 11 & 6 \\
$\begin{array}{l}\text { Transitory neurologic deficit } \\
\text { Meningism/meningitis (\%) }\end{array}$ & 0 & 4 & 5 & 4 \\
Died (\%) & 3 & 4 & 4 & 4 \\
\hline
\end{tabular}

Table 4. Results of Acoustic Neurinoma Surgery Via the Enlarge Middle Fossa Approach

\begin{tabular}{lllll}
\hline & \multicolumn{3}{c}{ Size } & \\
\cline { 2 - 4 } & $A$ & $B$ & $C$ & Total \\
\hline Operations (no.) & 25 & 98 & 83 & 206 \\
Complete tumor removal (no.) & 25 & 98 & 74 & 197 \\
Preoperative hearing loss & 24 & 81 & 63 & 168 \\
$\quad<90 \mathrm{~dB}$ (no.) & & & & \\
Cochlear nerve preserved (no.) & 25 & 84 & 46 & 155 \\
Preserved hearing (no.) & 17 & 46 & 23 & 86 \\
Postoperative/preoperative & 71 & 57 & 37 & 51
\end{tabular}

hearing (\%)

of 206 documented cases (Table 4). We have attributed this higher incidence to our increased endeavor to not sacrifice the main branch of the labyrinthine artery. It became evident that postoperative total deafness in spite of full structural preservation of the cochlear nerve was some times due to a disturbed vascular supply or, in cases of delayed hearing loss on the second or third postoperative day, to compression of the internal auditory meatus.

The subgrouping into the categories $\mathrm{A}$ ( $71 \%$ hearing preservation), B ( $57 \%$ hearing preservation), and C (37\% hearing preservation) underlines the importance of an early diagnosis and treatment of the smaller tumors. Average pure-tone threshold results (Table 5) as well as speech reception scores (Table 6) are given for all patients who could be followed postoperatively. It became obvious from these data that $72 \%$ of all operated ears had a preoperative hearing level of $60 \mathrm{~dB}$ hearing loss or better. This range of sensation levels could be preserved for $48 \%$ of the group A cases, $37 \%$ of the group B cases, and $29 \%$ of the group $\mathrm{C}$ cases. Our pure-tone thresholds were averaged for the frequencies $0.5,1.0,2.0$, and $4.0 \mathrm{kHz}$. The $4.0 \mathrm{kHz}$ frequency is usually not included in the averaged threshold scores reported in the literature.

Speech audiometry could be followed after an adequate postoperative period in only 110 patients. This deficit of data is due to incomplete documentation by the

Table 5. Pure-Toned Threshold*

\begin{tabular}{|c|c|c|c|c|c|c|c|c|}
\hline \multirow[b]{2}{*}{ Hearing Loss } & \multicolumn{4}{|c|}{ Preoperative (\%) } & \multicolumn{4}{|c|}{ Postoperative (\%) } \\
\hline & $A$ & $B$ & $C$ & Total & $A$ & $B$ & $C$ & Total \\
\hline $0-30 \mathrm{~dB}$ & 48 & 32 & 33 & 34 & 32 & 14 & 5 & 13 \\
\hline $31-60 \mathrm{~dB}$ & 32 & 36 & 41 & 38 & 16 & 23 & 24 & 21 \\
\hline $61-90 \mathrm{~dB}$ & 16 & 14 & 11 & 13 & 20 & 10 & 5 & 10 \\
\hline Deafness & 4 & 18 & 15 & 15 & 32 & 53 & 66 & 56 \\
\hline
\end{tabular}

*Average of $0.5,1,2,4 \mathrm{khz}$ in 197 patients. 
Table 6. Enlarged Extradural Middle Fossa Approach: Speech Audiometry

\begin{tabular}{|c|c|c|c|c|c|c|c|c|}
\hline \multirow[b]{2}{*}{ Hearing Loss } & \multicolumn{4}{|c|}{ Preoperative (\%) } & \multicolumn{4}{|c|}{ Postoperative (\%) } \\
\hline & $A$ & $B$ & C & Total & $A$ & $B$ & C & Total \\
\hline \multicolumn{9}{|c|}{ Speech reception threshold (50\% numbers) } \\
\hline $0-30 \mathrm{~dB}$ & 66 & 57 & 64 & 61 & 30 & 32 & 11 & 25 \\
\hline $31-60 \mathrm{~dB}$ & 24 & 25 & 19 & 22 & 40 & 19 & 19 & 22 \\
\hline $61-90 \mathrm{~dB}$ & 5 & 7 & 6 & 6 & - & 10 & 3 & 7 \\
\hline $90-120 \mathrm{~dB}$ & 5 & 11 & 11 & 11 & 30 & 39 & 67 & 46 \\
\hline \multicolumn{9}{|c|}{ Speech discrimination loss (monosyllables) } \\
\hline $0-30 \%$ & 37 & 48 & 53 & 49 & 45 & 38 & 19 & 32 \\
\hline $31-60 \%$ & 18 & 16 & 8 & 13 & 9 & 5 & 6 & 6 \\
\hline $61-90 \%$ & 27 & 9 & 8 & 10 & 9 & 10 & 6 & 9 \\
\hline Totally deaf & 18 & 27 & 31 & 28 & 37 & 47 & 69 & 53 \\
\hline
\end{tabular}

referring otologists. The figures in Table 6 demonstrate, however, that speech reception scores within a range of 0 to $60 \mathrm{~dB}$ could be attained by $47 \%$ of all ears with complete tumor removal, which had preoperative audition. Speech discrimination loss, and this is an important observation with regard to later support by a hearing aid, was less than $31 \%$ in $32 \%$ of the operated, preoperatively hearing, and postoperatively examined ears. Aside from other attributes, this result emphasizes the functional efficacy of the EMFA.

There was another, perhaps interesting, but until now not statistically verified observation: The ears with total postoperative deafness often have permanent tinnitus, which increases after noise exposure of the contralateral ear, but the postoperative tinnitus was generally less aggressive in the ears with persistent hearing capacity. This phenomenon deserves attention by other investigators.

\section{DISCUSSION}

The EMFA to the CPA as described herein is a technically difficult procedure. Those who have practical experience with it and also with the translabyrinthine and the lateral suboccipital approaches will certainly agree that these require less microsurgical efforts and operating time than the EMFA. Although the translabyrinthine exposure of the CPA avoids the microdissection of the cochlea and labyrinth, and is not complicated by the overlying facial nerve, the lateral suboccipital approach provides a broad exposure of the CPA and is a fast procedure. Good functional results regarding the facial nerve and low complication rates were reported for both methods.

The advantages are balanced by their disadvantages. These lie in the obligatory total deafness (translabyrinthine approach) or in the relative intraoperative compression of the cerebellum and the almost impossible exposure of the lateral third of the internal auditory meatus (lateral suboccipital approach). One can assume from the measurements of Dhomb and Chole ${ }^{17}$ that direct exposure of the meatal fundus is only occasionally possible because of its topographic obstruction by the labyrinth.

We believed that the EMFA deserved preference for the smaller acoustic neurinomas of diameters up to $3 \mathrm{~cm}$ in still hearing ears, and this decision was based basically on audiologic results. In spite of a complete tumor removal, the preoperative audition could be preserved in $71 \%$ of group A, in 57\% in group B, and in even $37 \%$ of those tumors that had gained a broad contact to the brainstem (group C). Improvement or deterioration of the persistent hearing was observed, and details will be published separately.

Remarkable rates of preservation of hearing were also reported for small intrameatal tumors removed by the classic midfossa approach of House. ${ }^{8-10}$ Larger tumors having grown into the CPA could be removed with preservation of hearing, however, only by utilizing one of the lateral suboccipital approaches. The success rates were 27 to $43 \% .{ }^{11-17}$ The completeness of the tumor removal from the fundus of the IAC was not documented in these articles, probably due to the poor visualization of the lateral meatal end. In our series of more than 200 cases no tumor recurrence became obvious over the observation time of up to 10 years.

With these implications in mind, we believe that the EMFA will remain our first choice and that future attempts should be concentrated on both the earlier diagnosis of acoustic neurinomas and an improved dissection technique to avoid injury to the labyrinthine artery.

\section{REFERENCES}

1. Wigand ME, Haid T, Berg M, Rettinger G: The enlarged transtemporal approach to the cerebello-pontine angle. Technique and indications. Acta Otorhinolaryngol Ital 2:571-582, 1982

2. Wigand ME, Rettinger G, Haid T, Berg M: Die Ausräumung von Oktavusneurinomen des Kleinhirnbrücken winkels mit transtemporalem Zugang über die mittlere Schädelgrube. HNO 33: 11-16, 1985

3. Wigand ME, Haid T, Berg M, Rettinger G: Transtemporal removal of acoustic neuromas from the CPA with preservation of hearing. In Myers E (ed): New Dimensions in OtorhinolaryngologyHead and Neck Surgery, vol. 2, Amsterdam: Elsevier Science Publishers BV, 1985

4. Hünig G, Berg M: Richtungshören bei Patienten mit seitendifferenter Schwerhörigkeit. HNO 39:27-31, 1991

5. Aurbach $\mathrm{G}$, Wigand ME: Chirurgisch-anatomische Orientierungshilfen für den erweiterten transtemporalen Zugang zum Kleinhirnbrückenwinkel. HNO 35:381-389, 1987

6. Wigand ME, Goertzen W, Berg M: Transtemporal planned partial resection of bilateral acoustic neuromas. Acta Neurochir (Wien) 92:50-54, 1988

7. Domb GH, Chole RA: Anatomical studies of the posterior petrous apex with regard to hearing preservation in acoustic neuroma removal. Laryngoscope 90:1769-1776, 1980

8. House WF: Surgical exposure of the internal auditory canal and its contents through the middle cranial fossa. Laryngoscope 71 : 1363-1385, 1961

9. House WF, Hitselberger WE: The middle fossa approach for removal of small acoustic tumors. Acta Otolaryngol (Stockh) 67: 413-427, 1969

10. Sanna M, Zini C, Mazzoni A, Gandolfi A, Pareschi R, Pasanisi E, 
Gamoletti R: Hearing preservation in acoustic neuroma surgery. Middle fossa versus suboccipital approach. Am J Otol 8:500506, 1987

11. Sterkers JM: Retro-sigmoid approach for preservation of hearing in early acoustic neuroma surgery. In Samii M, Jannetta P (eds): The Cranial Nerves. Berlin: Springer, 1981

12. Samii M, Turel KE, Penkert G: Management of seventh and eighth nerve involvement by cerebellopontine angle tumors. Clin Neurosurg 32:242-272, 1985

13. Frerebeau P, Benezech J, Uziel A, Coubes P, Segnarbieux F, Malonga $\mathrm{M}$ : Hearing preservation after acoustic neurinoma operation. Neurosurgery 21:197-200, 1987

14. Glasscock ME, McKennan KX, Levine SC: Acoustic neuroma surgery: The results of hearing conservation surgery. Laryngoscope 97:785-789, 1987

15. Nadol JB, Levine R, Ojemann RG, Martuza RL, Montgomery WW, De Sandoval PK: Preservation of hearing in surgical removal of acoustic neuromas of the internal auditory canal and cerebellar pontine angle. Laryngoscope 97:1287-1294, 1987

16. Fischer G, Morgon A, Fischer C, Bret PH, Massini B, Kzaiz M, Charlot $\mathrm{M}$ : Exérèse complète des neurinomes de l'acoustique. Préservation du nerf facial et de l'audition. Neurochirurgie (Paris) 33:169-183, 1987

17. Gardner G, Robertson JH: Hearing preservation in unilateral acoustic neuroma surgery. Ann Otol Rhinol Laryngol 97:55, 1988 